Supporting Information

\title{
A Polymer-in-salt Electrolyte with Enhanced Oxidative Stability for Lithium Metal Polymer Batteries
}

Haiping Wu, ${ }^{\mathrm{a} \dagger}$ Peiyuan Gao, ${ }^{\mathrm{b} \dagger}$, Hao Jia, ${ }^{\mathrm{a}}$ Lianfeng Zou, ${ }^{\mathrm{c}}$ Linchao Zhang, ${ }^{\text {a\# }}$ Xia Cao, ${ }^{\text {a Mark H. }}$ Engelhard, ${ }^{c}$ Mark E. Bowden, ${ }^{c}$ Michael S. Ding, ${ }^{d}$ Jiangtao Hu, ${ }^{a}$ Dehong Hu, ${ }^{c}$ Sarah D. Burton, ${ }^{c}$ Kang Xu, ${ }^{d}$ Chongmin Wang, ${ }^{c}$ Ji-Guang Zhang, ${ }^{a *} \mathrm{Wu} \mathrm{Xu}^{\mathrm{a} *}$

a Energy and Environment Directorate, Pacific Northwest National Laboratory, Richland, WA 99354, USA

b Physical and Computational Sciences Directorate, Pacific Northwest National Laboratory, Richland, WA 99354, USA

c Environmental Molecular Sciences Laboratory, Pacific Northwest National Laboratory, Richland, WA 99354, USA

d Battery Science Branch, U.S. Army Research Laboratory, Adelphi, MD 20783, USA

$\dagger$ These authors contributed equally in this work.

\# Present address: Key Laboratory of Materials Physics, Institute of Solid State Physics Chinese Academy of Sciences, Hefei, Anhui 230026, China

* Corresponding authors. E-mails: jiguang.zhang@pnnl.gov (J.-G. Zhang); wu.xu@ pnnl.gov (W. Xu) 
In order to investigate the influence of residual solvent in the polymer-in-salt electrolyte (PISE) on the properties and performance of PISEs, a polymer electrolyte was prepared using the conventional casting method. The polymer electrolyte consisted of lithium bis(fluorosulfonyl)imide (LiFSI), polyethylene oxide (PEO) and polyvinylidene fluoride (PVDF, Arkema) at a molar ratio of 1:0.5:2 and the mixture was dissolved in $\mathrm{N}, \mathrm{N}-$ dimethylformamide (DMF, Sigma-Aldrich) solvent. After the mixture was casted in a PTFE petri dish, most of the DMF was evaporated and the residual membrane was dried at $140{ }^{\circ} \mathrm{C}$ under vacuum with different drying time to get different polymer electrolyte membranes. The ionic conductivities and the Fourier-Transition infrared (FTIR) spectra of the obtained polymer electrolyte membranes were measured.

Figure S1 shows the temperature dependence of the ionic conductivities of the polymer electrolyte at different drying hours. It is seen that the conductivity drops greatly with extending the drying hour. This is because more solvent DMF molecules were evaporated from the polymer electrolyte membrane with the increase of the drying time and the ionic conduction became more difficult.

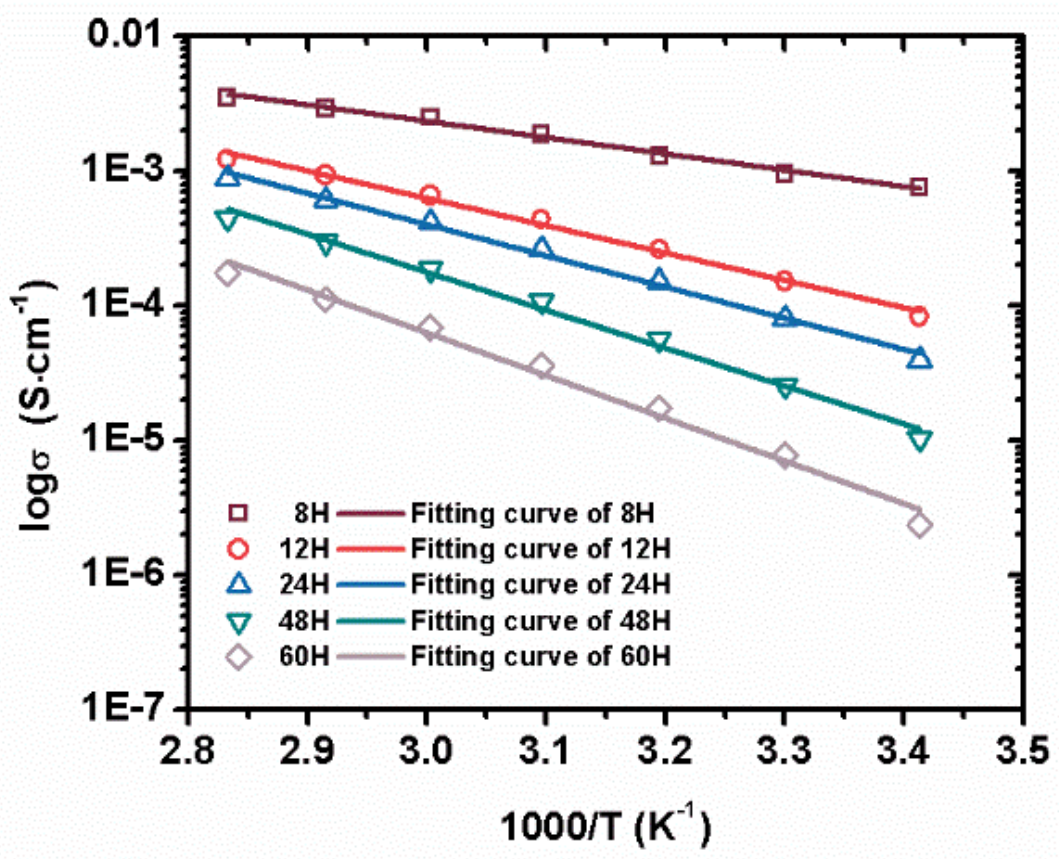

Figure S1. Ionic conductivity of polymer-in-salt electrolyte (LiFSI : PEO : PVDF $=1: 0.5: 2$, molar ratio) with different drying time. The polymer electrolyte was prepared through a solution casting method with DMF as solvent.

As seen from Figure S2 that exhibits the FTIR spectra of the polymer electrolyte membrane at different drying hours, the signal at $1650 \mathrm{~cm}^{-1}$ from $\mathrm{C}=\mathrm{O}$ of $\mathrm{DMF}$ decreases with the 
extension of the drying time; however, it still exists in the membrane after $48 \mathrm{~h}$ drying at 140 ${ }^{\circ} \mathrm{C}$ under vacuum, meaning that the casting solvent DMF has not completely removed. This is probably because DMF molecules have tighter coordination with $\mathrm{Li}^{+}$especially at high concentration after more DMF was evaporated. It's impossible to completely evaporate all solvent even under vacuum and at high temperature. This is probably the main reason that there are large variations in ionic conductivities of polymer electrolytes using solution casting method in literatures.

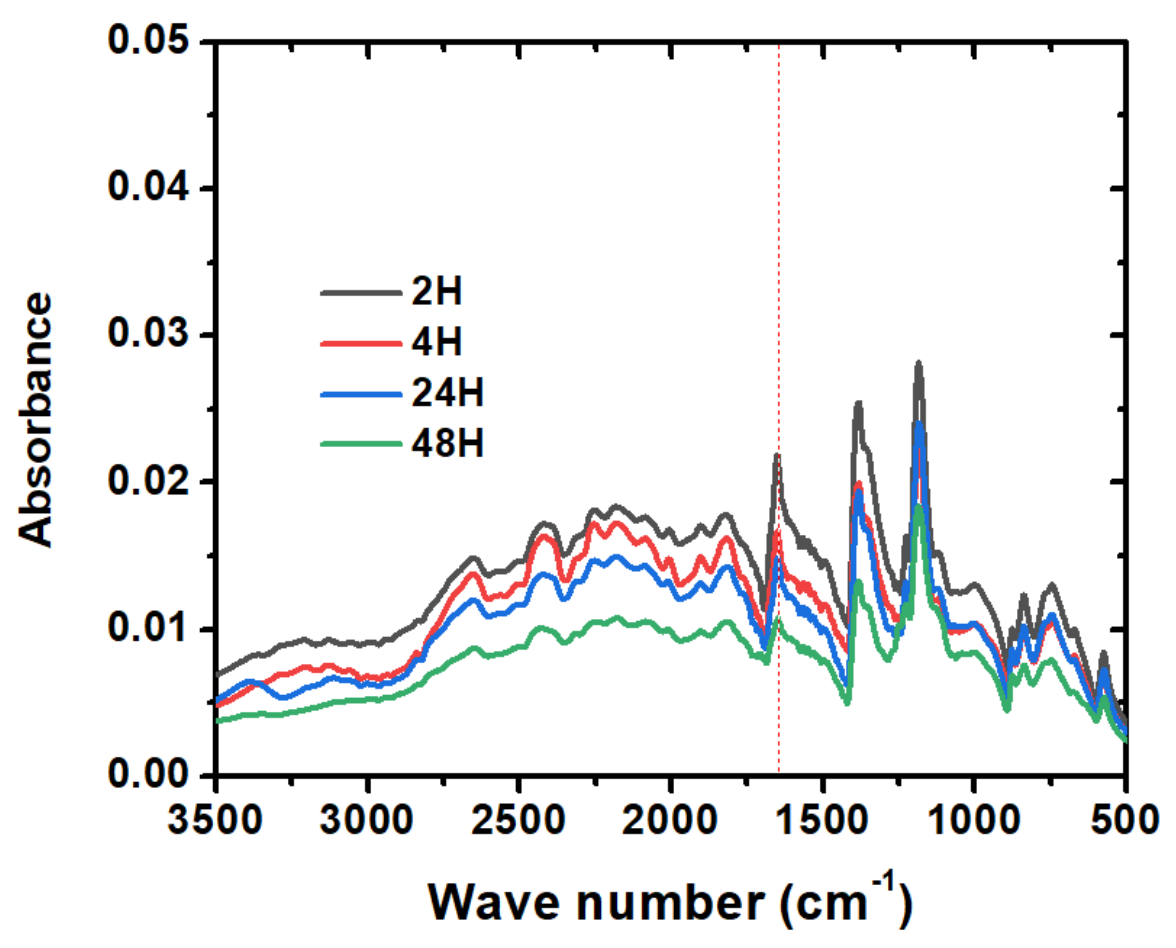

Figure S2. FTIR spectra of polymer-in-salt electrolyte (LiFSI : PEO : PVDF = $1: 0.5: 2$ ) with different drying time at $140{ }^{\circ} \mathrm{C}$ under vacuum. The signal of $1650 \mathrm{~cm}^{-1}$ is from $\mathrm{C}=\mathrm{O}$ of $\mathrm{DMF}$. 

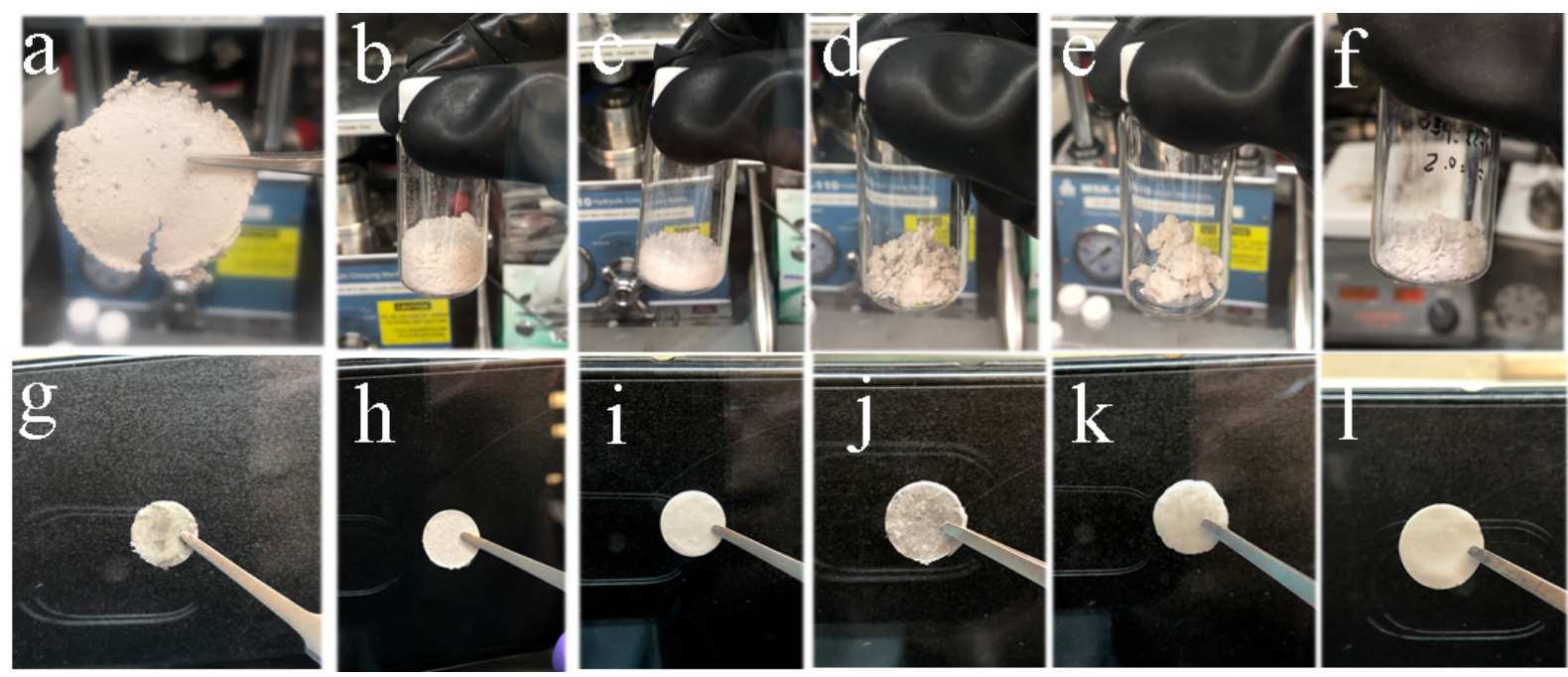

Figure S3. Photographs of (a, g) P(EO) ${ }_{16} \operatorname{LiFSI}$, (b, h) $\mathrm{P}(\mathrm{EO})_{8} \mathrm{LiFSI}$, (c, i) $\mathrm{P}(\mathrm{EO})_{4} \mathrm{LiFSI},(\mathrm{d}, \mathrm{j})$ $\mathrm{P}(\mathrm{EO})_{2} \mathrm{LiFSI}$, (e, k) P(EO) $)_{1} \mathrm{LiFSI}$ and (f, l) $\mathrm{P}(\mathrm{EO})_{0.5} \mathrm{LiFSI}$. (a-f) are mixtures, and (g-l) are discs.

$\mathrm{P}(\mathrm{EO})_{16} \mathrm{LiFSI}$ is a rigid plate after high-energy ball-milling and some zirconia oxide balls broke and mixed with $\mathrm{P}(\mathrm{EO})_{16} \mathrm{LiFSI}$ (Figure S3a). The XRD pattern of this sample (see the Figure S4) also shows typical peaks of zirconia oxide besides the peaks of PEO, indicating the existence of broken zirconia oxide balls. To avoid the misunderstanding of the properties of this solid polymer electrolyte due to the contamination of zirconia oxide, the further characterization of $\mathrm{P}(\mathrm{EO})_{16} \mathrm{LiFSI}$ was not performed in this work. 


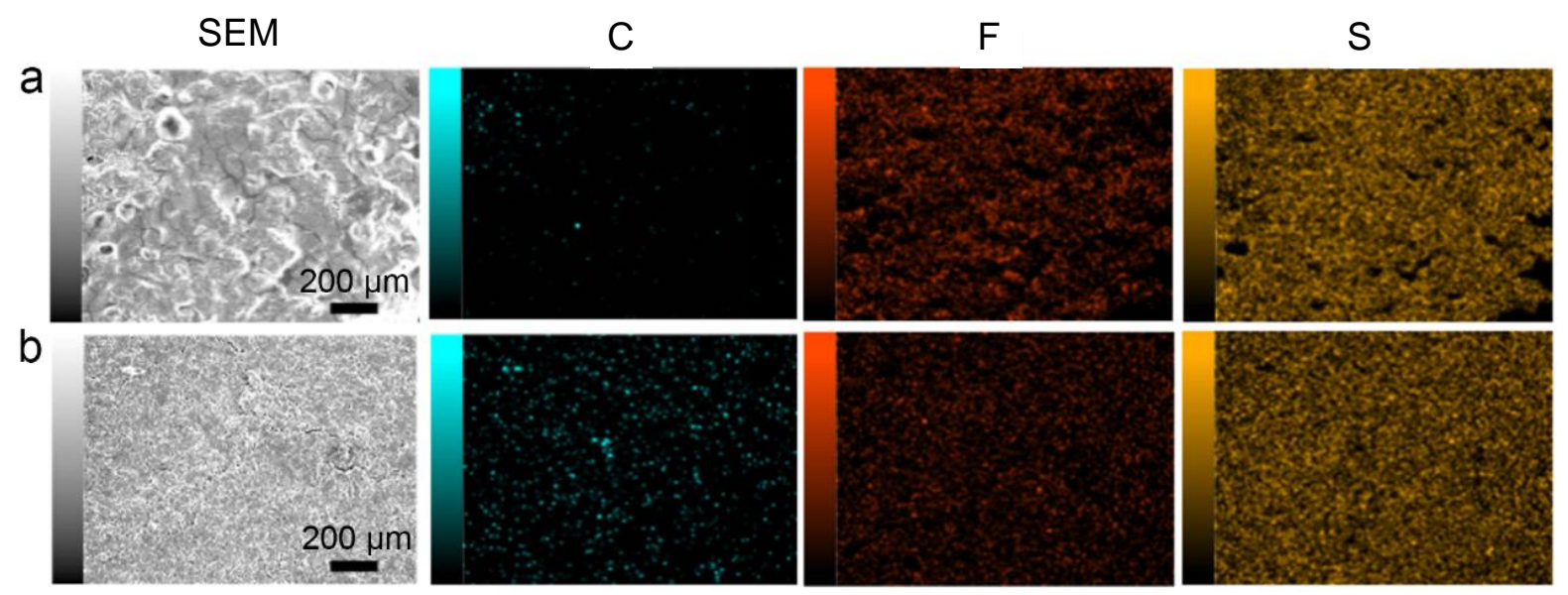

Figure S4. (a) SEM image and C, F, S distribution of P(EO) ${ }_{1}$ LiFSI. (b) SEM image and C, F, $\mathrm{S}$ distribution of $\mathrm{P}(\mathrm{EO})_{4} \mathrm{LiFSI}$. 


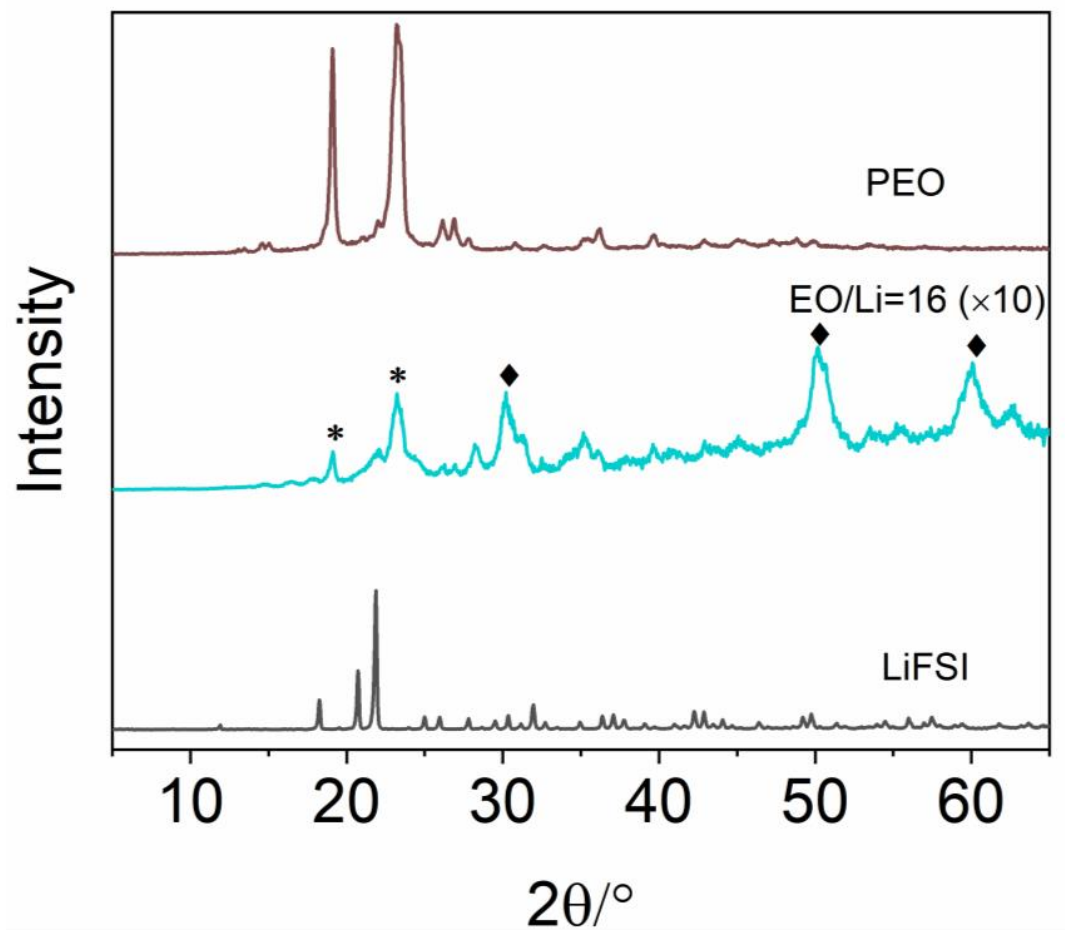

Figure S5. XRD patterns of PEO, P(EO) ${ }_{16} \mathrm{LiFSI}$ and LiFSI. * represents the typical peak of $\mathrm{PEO}$, represents the typical peak of zirconia oxide. 

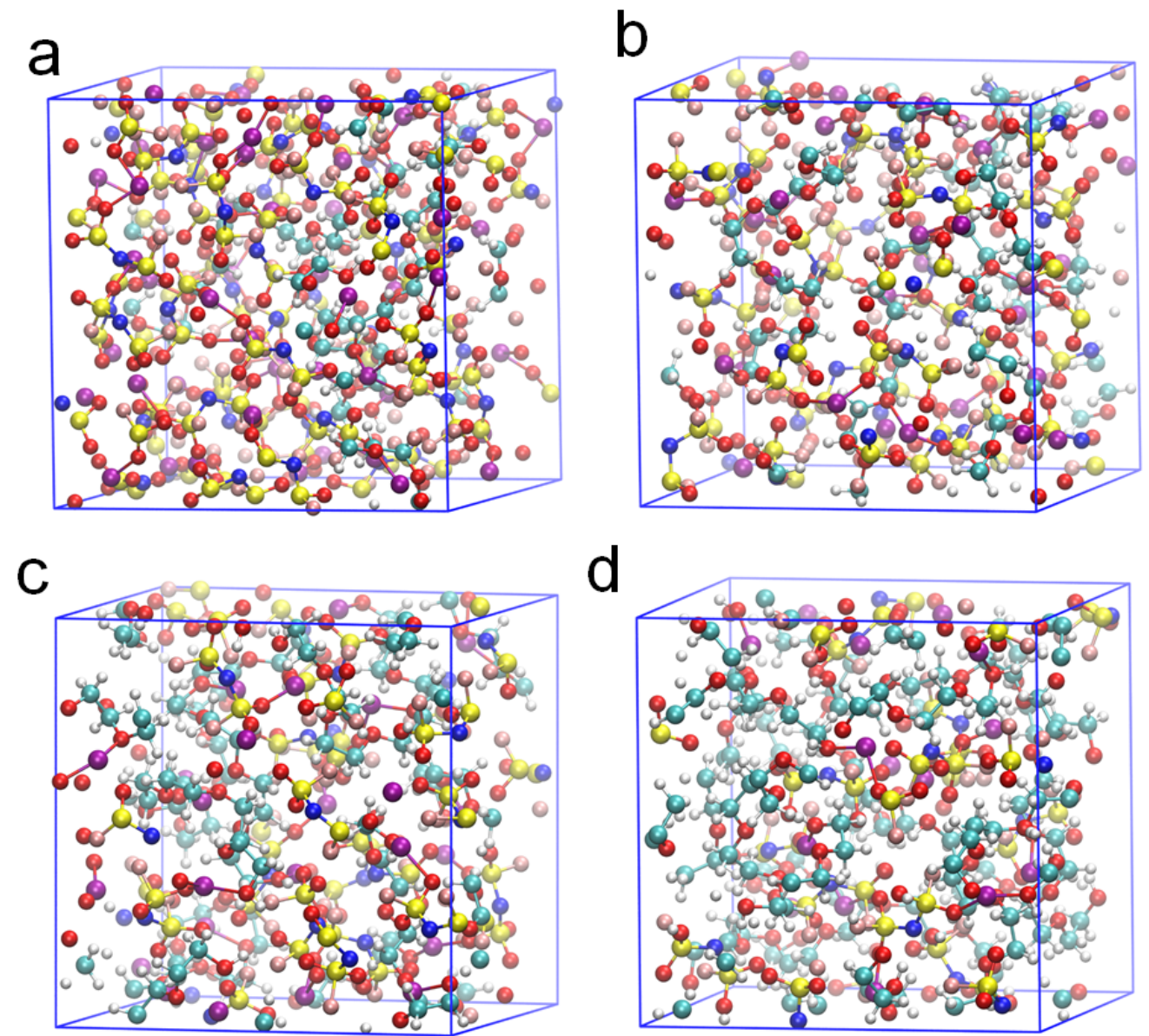

Figure S6. Snapshots of final configuration in PISE simulations as a function of EO/Li ratio: (a) $\mathrm{EO} / \mathrm{Li}=0.5$, (b) $\mathrm{EO} / \mathrm{Li}=1$, (c) $\mathrm{EO} / \mathrm{Li}=2$, and (d) $\mathrm{EO} / \mathrm{Li}=4$. Color code: $\mathrm{C}$ cyan, $\mathrm{O}$ red, $\mathrm{H}$ white, $\mathrm{N}$ dark blue, $\mathrm{S}$ yellow, F pink, Li purple. 


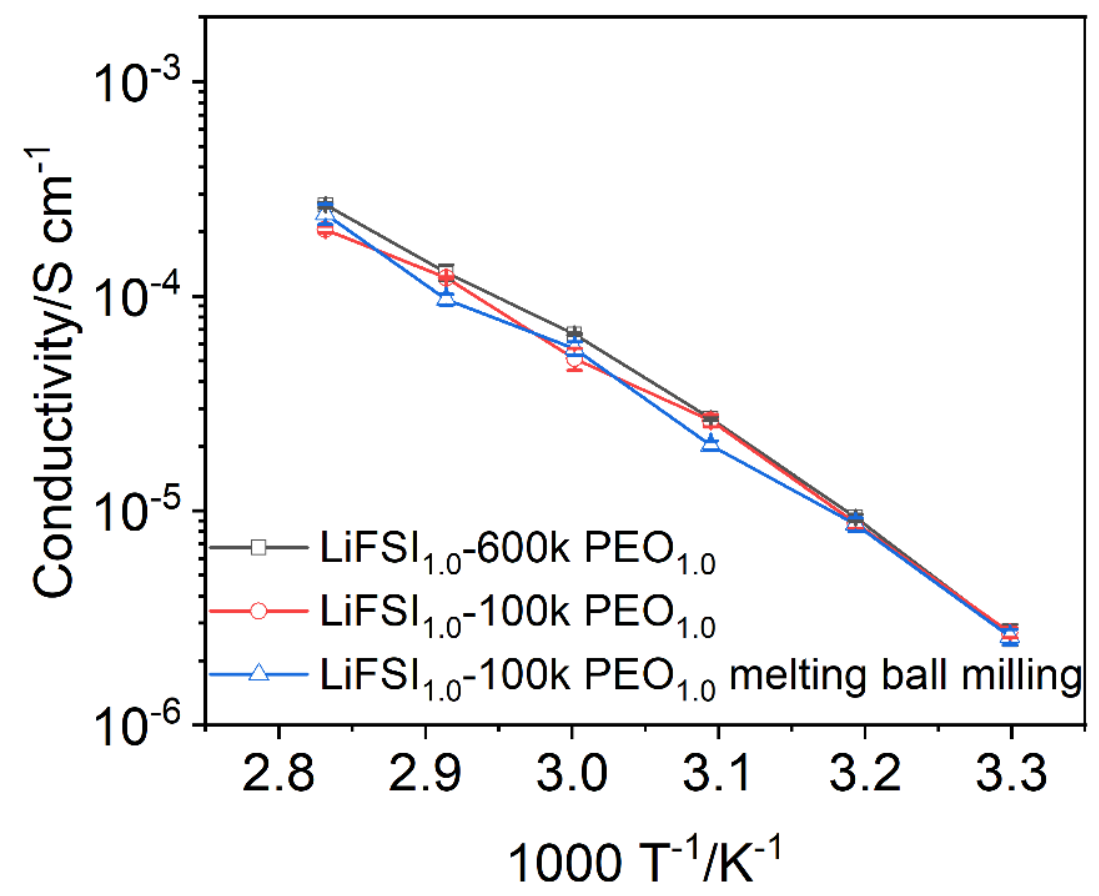

Figure S7. Temperature dependence of ionic conductivity of PISEs with different Mv PEO. 
Table S1. Ionic conductivities of PISE and HPEs with different ratios of ionic liquid Pyr14FSI at temperatures above $60{ }^{\circ} \mathrm{C}$.

\begin{tabular}{|c|c|c|c|}
\hline & $60{ }^{\circ} \mathrm{C}\left(\mathrm{S} \mathrm{cm}^{-1}\right)$ & $70{ }^{\circ} \mathrm{C}\left(\mathrm{S} \mathrm{cm}^{-1}\right)$ & $80{ }^{\circ} \mathrm{C}\left(\mathrm{S} \mathrm{cm}^{-1}\right)$ \\
\hline $\mathrm{P}(\mathrm{EO})_{1} \mathrm{LiFSI}$ & $6.6 \times 10^{-5}$ & $1.3 \times 10^{-4}$ & $2.7 \times 10^{-4}$ \\
\hline $\mathrm{P}(\mathrm{EO})_{1} \mathrm{LiFSI}$ & $1.7 \times 10^{-4}$ & $2.9 \times 10^{-4}$ & $6.1 \times 10^{-4}$ \\
\hline \multicolumn{4}{|l|}{$-P y r 14 F_{S I} I_{0.1}$} \\
\hline $\mathrm{P}(\mathrm{EO})_{1} \mathrm{LiFSI}$ & $2.8 \times 10^{-4}$ & $5.4 \times 10^{-4}$ & $8.2 \times 10^{-4}$ \\
\hline \multicolumn{4}{|l|}{$-P y r 14 F_{S I} I_{0.2}$} \\
\hline $\mathrm{P}(\mathrm{EO})_{1} \mathrm{LiFSI}$ & $6.4 \times 10^{-4}$ & $1.4 \times 10^{-3}$ & $2.2 \times 10^{-3}$ \\
\hline \multicolumn{4}{|l|}{-Pyr14FSI 0.3} \\
\hline $\mathrm{P}(\mathrm{EO})_{1} \mathrm{LiFSI}$ & $1.1 \times 10^{-3}$ & $1.8 \times 10^{-3}$ & $2.7 \times 10^{-3}$ \\
\hline -Pyr14FSI ${ }_{0.4}$ & & & \\
\hline
\end{tabular}




\section{Test proce dure s for ave rage $\mathrm{Li}$ Coulombic efficiency}

The average Li Coulombic efficiency (CE) of the HPE was tested in $\mathrm{Li} \| \mathrm{Cu}$ cells was tested according to the previous reports ${ }^{1,2}$ with certain modifications as following:

1) Initial Li plating for conditioning: Plate $1 \mathrm{mAh} \mathrm{cm}^{-2}$ at $0.1 \mathrm{~mA} \mathrm{~cm}-2$,

2) Initial Li striping for conditioning: Strip all $\mathrm{Li}$ at $0.1 \mathrm{~mA} \mathrm{~cm} \mathrm{~cm}^{-2}$ to $0.5 \mathrm{~V}$

3) Plate Li reserve (Qreservoir): $0.2 \mathrm{mAh} \mathrm{cm}^{-2}$ at $0.1 \mathrm{~mA} \mathrm{~cm}^{-2}$

4) Strip $Q$ cycle $=0.2 \mathrm{mAh} \mathrm{cm}^{-2}$ at $0.1 \mathrm{~mA} \mathrm{~cm}^{-2}$.

5) Plate $Q$ cycle $=0.2 \mathrm{mAh} \mathrm{cm}^{-2}$ at $0.1 \mathrm{~mA} \mathrm{~cm}^{-2}$

6) Repeat step 4 and 5 for 9 cycles.

7) Strip all $\mathrm{Li}\left(Q\right.$ strip) at $0.1 \mathrm{~mA} \mathrm{~cm}^{-2}$ to $0.5 \mathrm{~V}$

8) The average Li CE was calculated as $C E_{\text {avg. }}=\frac{n Q_{c y c l e, s t r i p}+Q_{\text {strip }}}{n Q_{\text {cycle } \text { plate }}+Q_{\text {reservoir }}}$

1. B. D. Adams, J. Zheng, X. Ren, W. Xu, J.-G. Zhang, Accurate Determination of Coulombic Efficiency for Lithium Metal Anodes and Lithium Metal Batteries, Adv. Energy Mater., 2018, $8(7), 1702097$.

2. X. Ren, L. Zou, X. Cao, M. H. Engelhard, W. Liu, S. D. Burton, H. Lee, C. Niu, B. E. Matthews, Z. Zhu, C. Wang, B. W. Arey, J. Xiao, J. Liu, J.-G. Zhang, W. Xu, Enabling HighVoltage Lithium-MetalBatteries under Practical Conditions, Joule, 2019, 3 (7), 1662-1676 


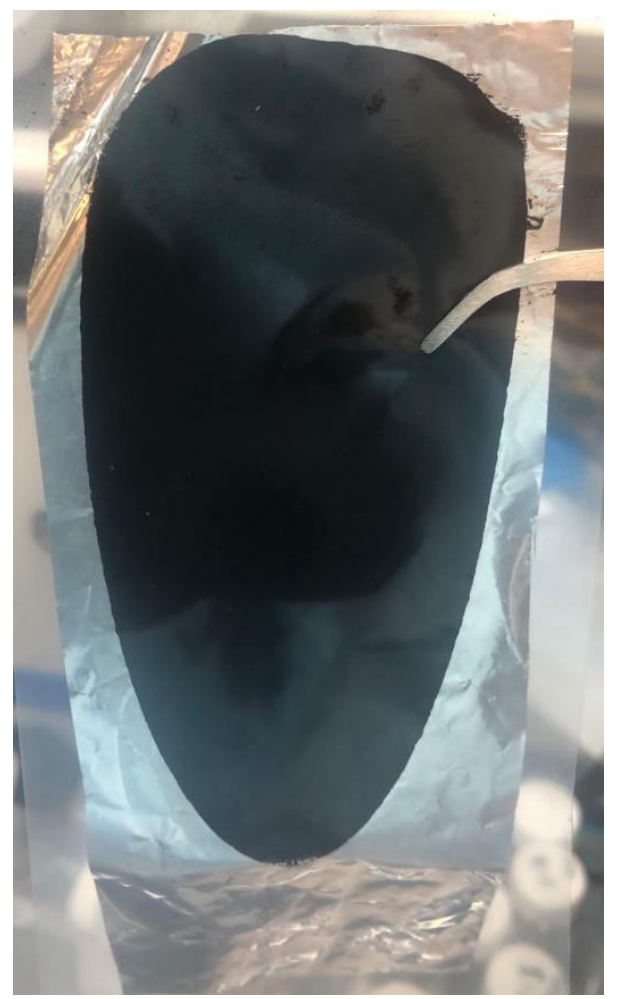

Figure S8. Photograph of the coated composite cathode consisting of 45 wt.\% NMC111, 5

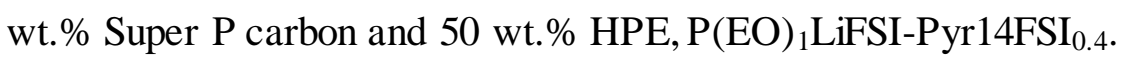



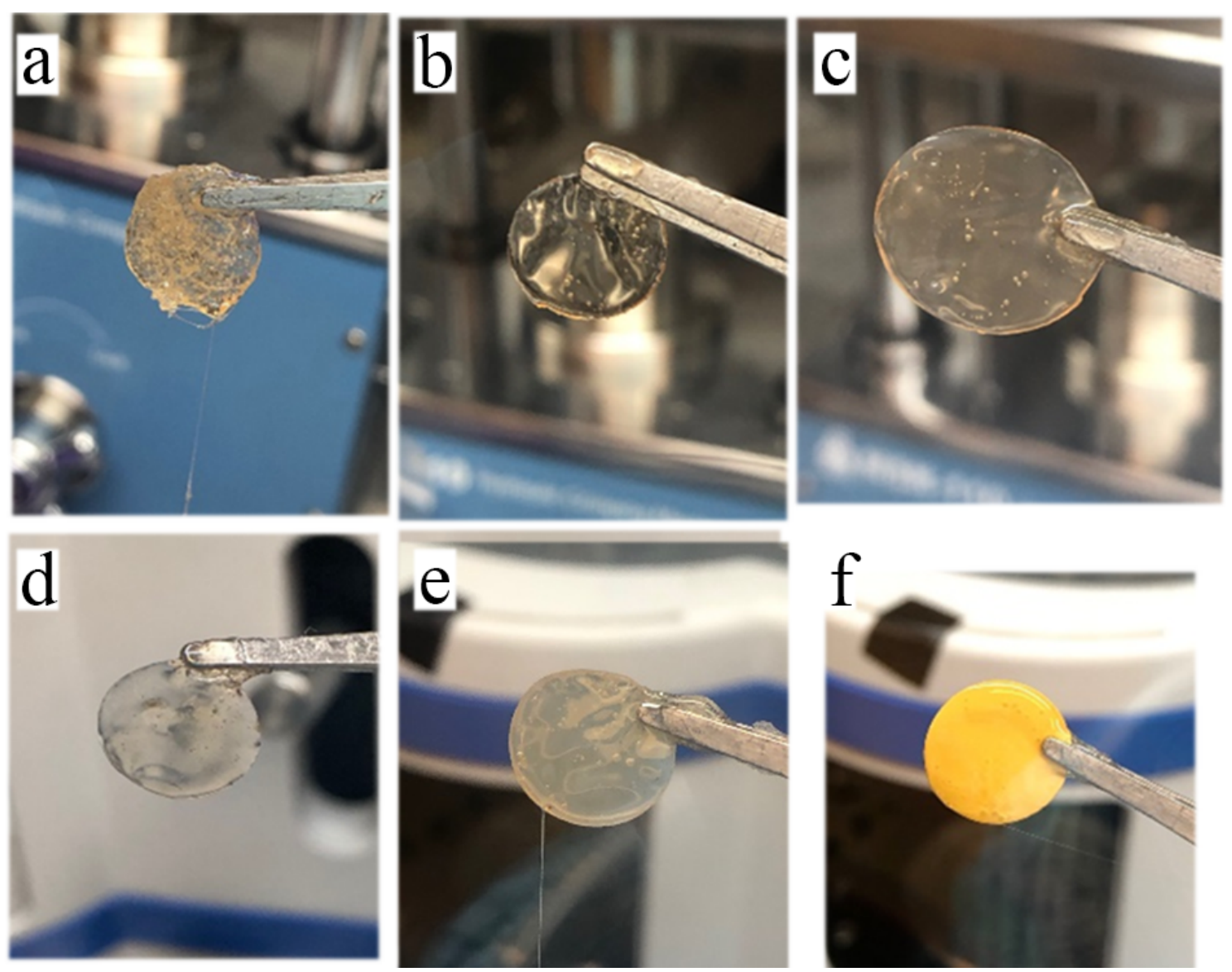

Figure S9. Photographs of different membranes soaked with $\mathrm{P}(\mathrm{EO})_{1} \mathrm{LiFSI}_{-\mathrm{Pyr} 14 \mathrm{FSI}} \mathrm{O}_{0.4}$ (HPE). (a) Nylon, (b) PCTE, (c) cellulose acetate, (d) Silver 20, (e) Celgard 3501, (f) PI. 
Table S2. Simulation systems

\begin{tabular}{ccccc}
\hline & 1 & 2 & 3 & 4 \\
\hline EO/Li (molar ratio) & 0.5 & 1 & 2 & 4 \\
& & & & \\
\hline $\begin{array}{c}\text { PEO/LiFSI } \\
\text { (molecular ratio) }\end{array}$ & $3: 48$ & $4: 32$ & $6: 24$ & $8: 16$ \\
& & & & \\
\hline
\end{tabular}

